
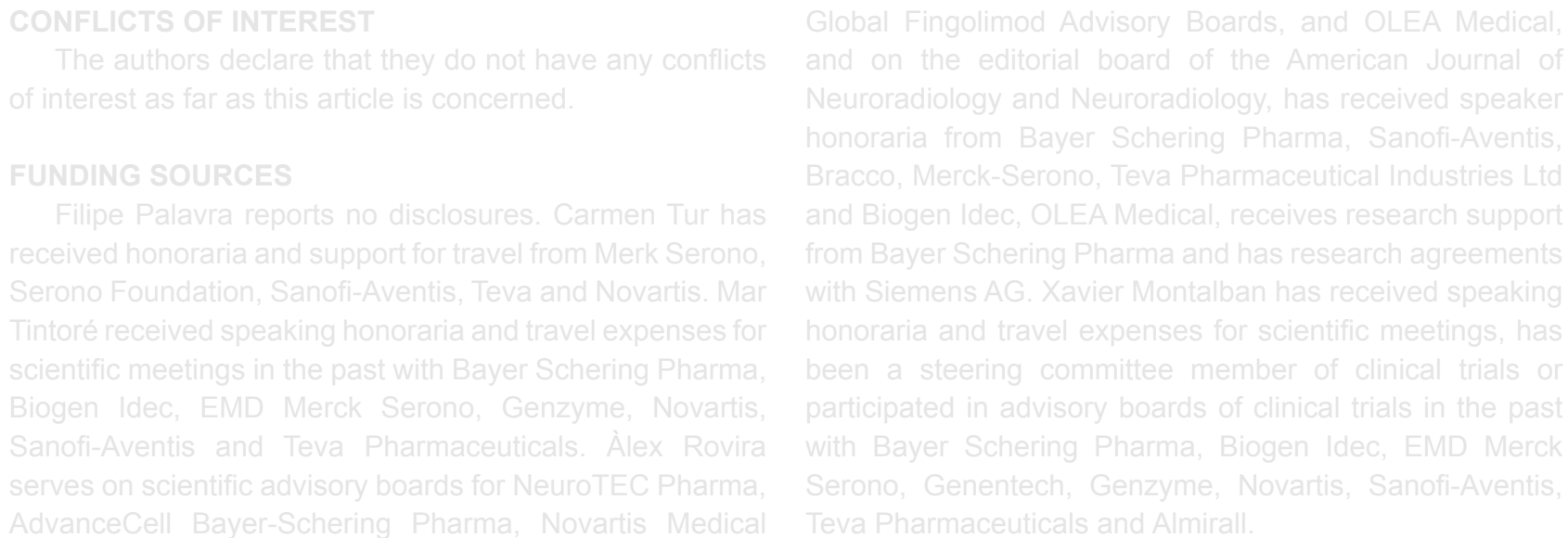

\title{
Schistosomose e Apendicite Aguda
}

\author{
Schistosomiasis and Acute Appendicitis
}
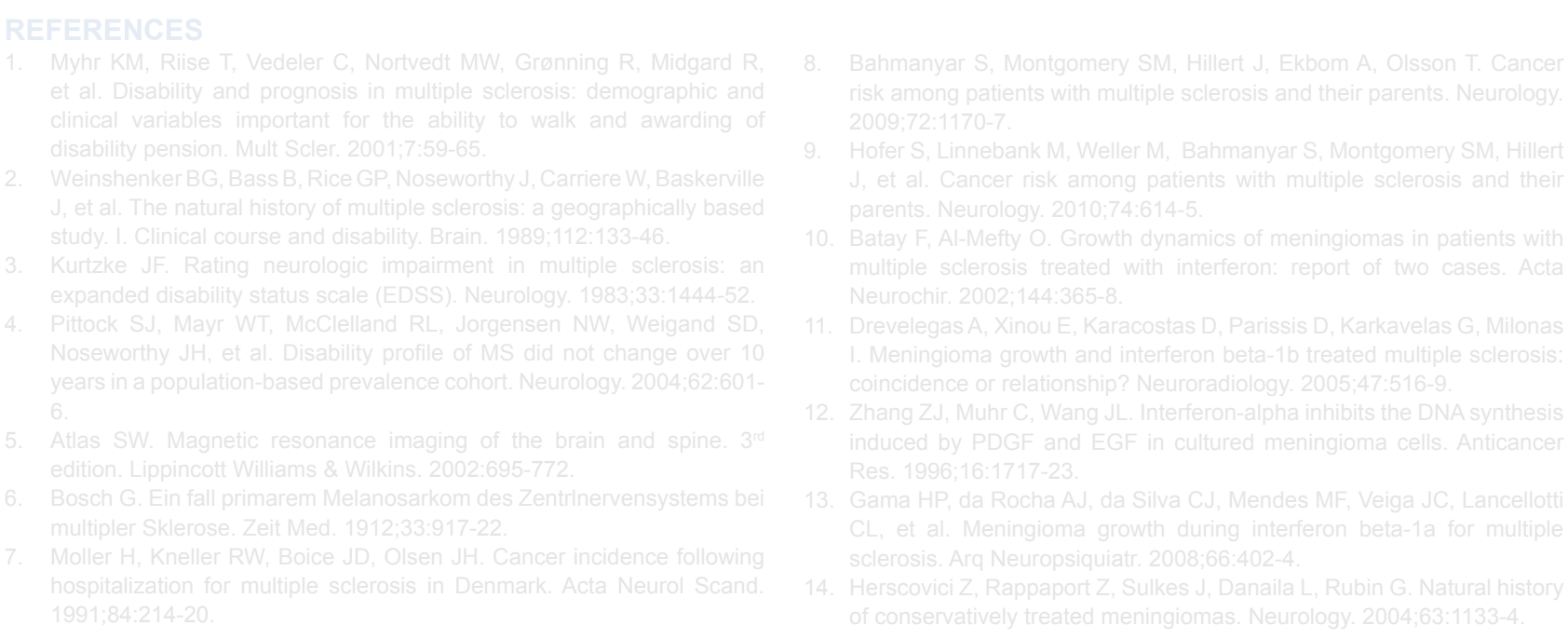

\author{
Jacinta FIGUEIREDO ${ }^{1}$, Ângela SANTOS², Horácio CLEMENTE², Augusto LOURENÇO², Sandra COSTA ${ }^{3}$ Maria Amélia \\ GRÁClO ${ }^{4}$, Silvana BELO 4 \\ Acta Med Port 2014 May-Jun;27(3):396-399
}

\section{RESUMO}

A ocorrência de casos de apendicite aguda causada por Schistosoma haematobium e S. mansoni é uma situação clínica que tem vindo a ser observada em doentes submetidos a apendicectomia na urgência do Hospital Américo Boavida em Luanda. Atendendo à prevalência e morbilidade da schistosomose (ou bilharziose) no país, admitimos que esta infeção parasitária seja um fator causal muito frequente de apendicite, particularmente nas populações mais expostas à transmissão. Descrevemos dois casos de apendicite aguda associada à presença de ovos destas espécies de Schistosoma atingindo a mucosa do apêndice visíveis por histologia, em doentes naturais de zonas endémicas de Angola, com exposição precoce aos parasitas, o que justifica a cronicidade da infeção. Consideramos que a divulgação destes casos será particularmente relevante para as equipas de cirurgia geral e de anatomopatologia, atendendo à

1. Serviço de Urologia. Hospital Américo Boavida. Luanda. Angola.

2. Serviço de Cirurgia Geral. Hospital Américo Boavida. Luanda. Angola.

3. Serviço de Anatomia Patológica. Hospital Américo Boavida. Universidade Agostinho Neto. Luanda. Angola.

4. Unidade de Parasitologia Médica. Grupo de Helmintologia e Malacologia Médicas. Instituto de Higiene e Medicina Tropical. Universidade Nova de Lisboa. Lisboa. Portugák

Recebido: 08 de Janeiro de 2014 - Aceite: 02 de Abril de 2014 | Copyright (C) Ordem dos Médicos 2014 
necessidade de execução sistemática de exames histológicos em todas as peças operatórias relacionadas.

Palavras-chave: Apendicite/ parasitologia; Schistosomose; Angola; África.

\section{ABSTRACT}

Acute appendicitis associated to Schistosoma haematobium and S. mansoni infection has been found in patients submitted to urgent appendectomy at the Hospital Américo Boavida in Luanda. Due to the high prevalence and morbidity caused by schistosomiasis (or bilharziasis) in the country, we suspect that the involvement of Schistosoma infection on appendicular pathology could be very frequent, in particular for those individuals more exposed to the parasite transmission. We report two clinical cases of acute appendicitis whose surgical specimens of the appendix revealed S. haematobium and S. mansoni eggs in histological samples. The reported patients live in endemic areas and have been exposed to schistosome during childhood, which may explain the infection's chronicity. Information of these clinical cases could be relevant, particularly for surgery specialists and clinical pathologists, due to the possibility of finding more patients with concurrent appendicitis and schistosomiasis.

Keywords: Appendicitis/parasitology; Schistosomiasis; Angola; África.

\section{INTRODUÇÃO}

A apendicite é uma inflamação do apêndice íleo cecal causada, frequentemente, por ulceração da mucosa de causa viral, obstrução por fecalitos, hiperplasia linfática, tumores ou doenças inflamatórias É uma urgência cirúrgica frequente na adolescência mas pode ocorrer em qualquer idade e estima-se que afete mais de $7 \%$ da população mundial; as infeções parasitárias como a ascaridiose ou a enterobiose podem causar complicações, com perfuração e peritonite. ${ }^{1,2}$ Diversas observações clínicas têm evidenciado a participação direta de Schistosoma spp na etiologia da apendicite aguda, admitindo-se que representem cerca de $28,6 \%$ dos casos de apendicite em áreas endémicas. ${ }^{3,4}$ Os autores consideram importante a realização sistemática de exames histológicos das peças operatórias em casos de apendicite aguda na região.

A schistosomose é a segunda doença parasitária com maior impacte em saúde pública nas regiões tropicais de África, América Latina e Ásia, estimando-se em mais de 207 milhões o número de indivíduos afetadas, dos quais $85 \%$ residem na África Subsariana. Calcula-se que cerca de 120 milhões tenham sintomas e 20 milhões apresentem sequelas da doença. ${ }^{5,6}$

Em Angola, são endémicas as espécies Schistosoma haematobium, agente causal a schistosomose urogenital (predominante em África), amplamente distribuída em todo o território, com prevalências de 29 a $49 \%$, sendo causa frequente de morbilidade e $S$. mansoni, responsável pela forma intestinal da doença, com uma distribuição mais restrita. ${ }^{7,8}$

O processo patológico consiste numa inflamação granulomatosa em relação com os ovos dos parasitas, que pode ser invasiva e atingir órgãos distantes por embolização. ${ }^{5,6} \mathrm{Na}$ schistosomose urogenital, os ovos depositados atingem normalmente o plexo venoso da bexiga, ureteres e rins e do trato genitourinário, provocando cistite com hematúria terminal, prostatites e cervicites. ${ }^{1,2} \mathrm{Na}$ schistosomose intestinal, as lesões causadas pelos ovos localizam-se principalmente nos plexos venosos mesentéricos do intestino, podendo dar origem a um espectro de manifestações clínicas, incluindo polipose do colon, esplenomegalia, hipertensão porto-pulmonar com hematémese.

No decurso das nossas observações sobre patologia urológica causada por $S$. haematobium no Hospital Américo Boavida ( $\mathrm{HAB}$ ), dos doentes com cistite crónica, oito tinham antecedentes de internamento na urgência, tendo sido operados com diagnóstico de apendicite aguda. O resultado anatomopatológico revelou apêndice com numerosos ovos de $S$. haematobium e, num caso, ovos de $S$. mansoni.

\section{CASO CLÍNICO 1}

Doente do sexo feminino, de 23 anos de idade, natural do Bengo, com antecedente de contacto e imersão em coleções hídricas (rios, lagoas) potencialmente infetadas com cercárias de Schistosoma. Refere início da sintomatologia cerca de dois anos com história de hematúria terminal, tendo sido na altura medicada com Praziquantel na dose de 4 comprimidos (sic). Acorreu à urgência com queixas de dejeções pastosas sem sangue durante cerca de um mês. Dois dias depois inicia febre de $38,4^{\circ} \mathrm{C}$, paragem de emissão de gases e fezes, vómitos e falta de apetite.

Ao exame físico do abdómen, manifestava dor à palpação, com defesa muscular marcada, sinais de Rovsing e de Blumberg duvidosos. Ao exame vaginal referiu dor no fundo de saco de Douglas à direita, dedo de luva sem secreção.

Em relação aos exames complementares, as análises do sangue mostraram leucocitose de 17000 células $/ \mathrm{mm}^{3}$, exame de urina e de fezes negativos para microrganismos e parasitas. O RX simples do abdómen mostrou presença de ansa sentinela. A ecografia pélvica e abdominal mostrou aumento de volume do apêndice e hiperecogenicidade da parede vesical.

A doente foi internada com terapia antibiótica e com hidratação. Após oito horas foi submetida a laparatomia exploradora e apendicectomia cujo resultado histológico revelou numerosos ovos de $S$. haematobium (Fig. 1). Foi medicada com Praziquantel $(40 \mathrm{mg} / \mathrm{kg})$.

\section{CASO CLÍNICO 2}

Doente de 28 anos de idade, sexo masculino, natural de Malange, com antecedentes de hematúria terminal na infância, acorreu à urgência do HAB com história de evolução de 24 horas caraterizada por dor abdominal de início insidioso no hipogastro e na fossa ilíaca direita, posteriormente passando a difusa com maior intensidade (no ponto de MacBurney). Teve febre de $38^{\circ} \mathrm{C}$, náuseas e vómitos de conteúdo alimentar.

Ao exame físico, no abdómen, revelou dor a palpação com defesa muscular marcada, sinal de Blumberg e de Rovsing positivos e as análises de sangue mostraram leu- 


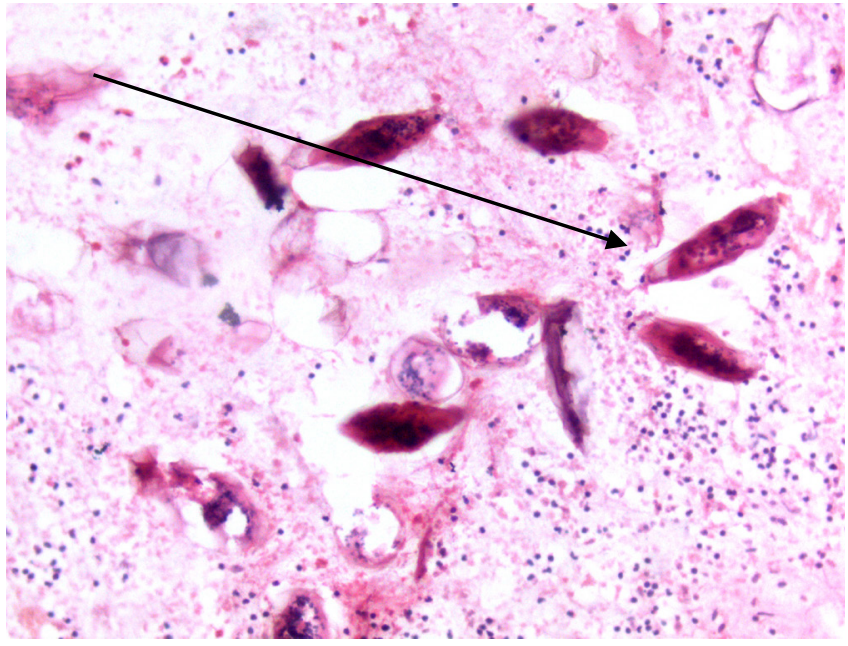

Figura 1 - Tecido de apêndice e válvula ileocecal ( $5 \mathrm{~mm}$ fixado em parafina) com numerosos ovos de $S$. haematobium calcificados. Coloração com Hematoxilina-Eosina (HEX 400-1)

cocitose de 17000 células/ mm³. O RX simples do abdómen apresentou presença de ansa sentinela. Foi efetuado diagnóstico diferencial para adenite mesentérica (por ecografia abdominal), infeções do trato urinário (ITU) e isquémia mesentérica do intestino ou volvo. O exame ecográfico abdominal revelou presença de processo inflamatório com sinais suspeitos de apendicite aguda.

$O$ doente foi internado, hidratado e iniciou terapêutica antibiótica com Ampicilina $1 \mathrm{~g} \mathrm{EV} \mathrm{de} \mathrm{6/6} \mathrm{horas} \mathrm{sendo} \mathrm{sub-}$ metido a tratamento cirúrgico com laparotomia exploradora infraumbilical. Durante a intervenção identificou-se líquido sero-purulento $(200 \mathrm{ml})$ sem cheiro na cavidade, apêndice com edema e necrose da região distal. A peça foi enviada ao serviço de anatomopatologia cujo resultado histopatológico revelou apendicite fleimonosa com presença de numerosos ovos de S. mansoni (Fig. 2). Durante o período de internamento (três dias), foi tratado com Praziquantel (40 $\mathrm{mg} / \mathrm{kg}$ ), com segundo ciclo de tratamento ao $15^{\circ}$ dia.

\section{DISCUSSÃO}

O envolvimento dos schistosomas na patologia apendicular tem sido referido nalgumas regiões endémicas bem como em países fora das áreas de endemia (Europa, América do Norte) onde diversos casos têm sido diagnosticados em indivíduos oriundos daquelas regiões. ${ }^{1,4,9}$ Estudos realizados no Egipto demonstraram que a apendicite aguda causada pela schistosomose variava de $0,02 \%$ a $6,3 \%{ }^{8}$ enquanto na Nigéria 2,2\% dos exames histológicos de apendicectomias apresentavam ovos de Schistosoma. ${ }^{3}$

Os dois casos relatados mostraram ter antecedentes, na infância, de contacto com coleções hídricas, potenciais

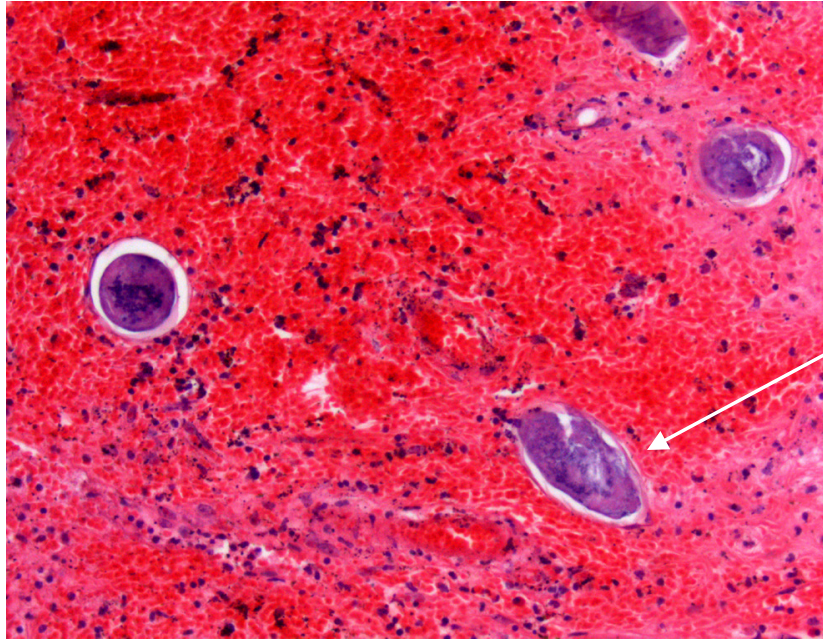

Figura 2 - Tecido de apêndice ( $6 \mathrm{~mm}$ fixado em parafina de doente com apendicite aguda) mostrando numerosos ovos de S. mansoni (esporão lateral). Coloração com Hematoxilina-Eosina (HEX 4001)

focos de transmissão de schistosomose, o que justifica a cronicidade da infeção. Apesar de não terem sido divulgados, existem registos de exames histológicos de apêndices cecais com evidência de ovos de S. haematobium e S. mansoni em Angola, o que reforça a possibilidade da sua elevada persistência. Este achado, aliado às observações na prática clínica de um de nós e a estudos epidemiológicos, ${ }^{7}$ vem reforçar a necessidade de implementação de medidas de controlo para a schistosomose,$^{10}$ incluindo o rastreio e tratamento da população adulta residente em áreas endémicas. Considerando a ampla distribuição e prevalência da parasitose no país, admitimos que a schistosomose seja uma causa de apendicite aguda mais frequente do que se estima, sobretudo em zonas de elevada endemicidade.

\section{AGRADECIMENTOS}

A Idália Conde, do Hospital Américo Boavida pelo apoio nas preparações histológicas e a Jorge Atouguia, do Instituto de Higiene e Medicina Tropical, pela revisão deste trabalho.

\section{CONFLITOS DE INTERESSE}

Os autores declaram que não houve conflito de interesses na realização deste trabalho.

\section{FONTES DE FINANCIAMENTO}

Este artigo foi patrocinado pela Fundação para a Ciência e a Tecnologia, Bolsa de Doutoramento (BD/51475), Unidade de Parasitologia e Microbiologia Médicas (UPMM)/ FCT Lisboa-Portugal.

view of schistosomal appendicitis in south western Nigeria. Trop Gastroenterol. 2009;30:230-2.

4. Lopez de Cenarruzabeitia I, Landolfi S, Armengol Carrasco M. Intestinal schistosomiasis as unusual aetiology for acute appendicitis, nowadays a rising disease in Western Countries. Case Rep Infect Dis. 2012;2012:896820. 
5. World Health Organization. Weekly Epidemiological Record. WHO 2010;18:157-64.

6. Rey L. Parasitologia, parasitas e doenças parasitárias do homem nas Américas e na Africa. $3^{a}$ ed. Rio de Janeiro: Guanabara Koogan; 2001.

7. Ministério da Saúde de Angola. Inquérito nacional sobre a prevalência das helmintíases intestinais e das schistosomíses em crianças de idade escolar. Luanda: MINSA; 2005.

8. Grácio MA. Incidência da bilharziosevesical em escolares do distrito de
Luanda II- áreas de Quifangondo, Funda, Viana, Lagoa Quilunda e Lagoa Panquila. J Soc Cien Med Lis.1980;144:71-9.

9. Nandipati K, Parithivel V, Niazi M. Schistosomiasis: a rare cause of acute appendicitis in the African American population in the United States. Am Surg. 2008;74:221-3.

10. Warren DJ Jr, Christopher WJ, Franklin CL. Campbell-Walsh Urology CD. 8th ed. London: Saunders Elsevier; 2002.

Chronic Hypocalcemia due to Anti-Calcium Sensing Receptor Antibodies

Pedro MARQUES1, Rita SANTOS1, Branca CAVACO², Valeriano LEITE'

Acta Med Port 2014 May-Jun;27(3):399-402

RESUMO

Introdução: O hipoparatiroidismo cursa com hipocalcemia e é mais frequentemente registado após cirurgia cervical. A etiologia autoimune é mais rara e difícil de diagnosticar.

Caso clínico: Mulher, 52 anos, sem antecedentes pessoais, medicamentosos ou familiares relevantes, referenciada por hipocalcemiz e calcificação dos núcleos da base, detetados no decurso de investigação de quadro de mialgias. Além de hipocalcemia (4,6 mg/dL ol verificada hiperfosfatemia $(8.7 \mathrm{ma} / \mathrm{dL}$ ). hormona paratiroideia indetetável. calciúria, fosfatúria e magnesúria baixas. A análise moAtualmente está assintomática e normocalcémica sob teranêutica com cálcio e viłamina D.

Discussão: Embora rara, a hipocalcemia por hipoparatiroidismo autoimune deve ponderar-se em adultos sem antecedentes de cirur gia cervical, medicação hipocalcemiante, história familiar ou fenótipo sugestivo de doença genética. Hormona paratiroideia diminuída (0.

Palavras-chave: Hipocalcemia; Hipoparatiroidismo; Receptores de Detecção de Cálcic .

\section{ABSTRACT}

Introduction: Hypoparathyroidism is an entity associated with hypocalcemia, more frequently a consequence of neck surgery. An autoimmune etiology is rare and its diagnosis difficult to establish.

Clinical report: 52 vear-old woman, with irrelevant past medical history and no significant familial conditions, referred because of hypocalcemia and basal ganglia calcifications, detected in the course of investigation of myalgias. Besides hypocalcemia (4.6 mo $\mathrm{dL}$ ), hyperphosphatemia $(8.7 \mathrm{mg} / \mathrm{dL})$, undetectable parathyroid hormone and low urinary calcium, phosphorus and magnesium were present. Molecular analysis of CaSR gene excluded germinal mutations. Anti-calcium sensing receptor antibodies (anti-CaSR) were oresent. The patient is asymptomatic and normocalcemic under treatment with calcium and vitamin $\square$

Discussion: Although rare, hvpocalcemia due to anti-CaSR hypoparathyroidism must be considered in the absence of previous neck surgery, hypocalcemic drugs, familial history or phenotype suggesting a genetic disorder. Low or undetectable parathyroid hormone excludes pseudohypoparathyroidism and anti-CaSR positivity establishes the diagnosis

Keywords: Hypocalcemia; Hypoparathyroidism; Autoantibodies; Receptors, Calcium-Sensing

\section{INTRODUCÃC}

A hipocalcemia é definida como baixo nível sérico de cálcio ionizado ou de cálcio total corrigido à albumina. ${ }^{1} \mathrm{~A}$ calcemia é mantida em niveis fisiológicos sobretudo pela ação da hormona paratiroideia (PTH) e vitamina D activa $\left.1,25(\mathrm{OH})_{2} \mathrm{D}\right)$. Várias situações cursam com hipocalcemia sendo o hipoparatiroidismo (HipoPT) a mais frequente. ${ }^{2}$ A ecreção baixa ou inexistente de PTH é inadequada para nobilizar cálcio ósseo, reabsorver cálcio a nivel renal e estimular a 1a-hidroxilase renal, resultando em niveis baixos de $1.25(\mathrm{OH})$, D e deficiente absorcão qastrointestinal de cálcio. ${ }^{1,3} \bigcirc$ HipoPT pode ser congénito ou adquirido sendo a causa mais frequente a cirurgia cervical. ${ }^{1}$ (Tabela 1)
A autoimunidade é uma causa de HipoPT que pode aparecer isoladamente ou como componente de sindromes poliglandulares autoimunes, nomeadamente do tipo 1.4-6 A primeira evidência de HipoPT autoimune foi apontada por Blizzard em 1966, que identificou anticorpos anti-paratiróide. ${ }^{7}$ Em 1993 clonou-se pela primeira vez o recetor sensível do cálcio (CaSR)8 e em 2003/2004 documentaram-se anticorpos estimuladores e inibidores do recetor sensive do cálcio (anti-CaSR).9,10 Os anti-CaSR estimuladores vãc ativar o recetor condicionando uma diminuição da secreçãc de PTH. 
Jacinta FIGUEIREDO, Ângela SANTOS, Horácio CLEMENTE, Augusto LOURENÇO, Sandra COSTA, Maria Amélia GRÁCIO, Silvana BELO

\section{Schistosomose e Apendicite Aguda \\ Acta Med Port 2014:27:396-399}

Publicado pela Acta Médica Portuguesa, a Revista Científica da Ordem dos Médicos

Av. Almirante Gago Coutinho, 151

1749-084 Lisboa, Portugal.

Tel: +351218428215

E-mail: submissao@actamedicaportuguesa.com

www.actamedicaportuguesa.com

ISSN:0870-399X | e-ISSN: 1646-0758

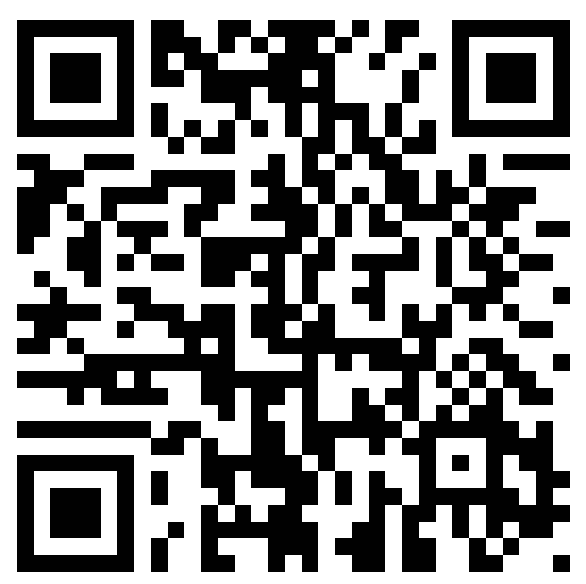

ACTA MÉDICA

PORTUGUESA 